\title{
Deep Brain Stimulation in Moroccan Patients With Parkinson's Disease: The Experience of Neurology Department of Rabat
}

\section{OPEN ACCESS}

Edited by:

Nilesh Bhailalbhai Patel,

University of Nairobi, Kenya

Reviewed by:

Adam Olding Hebb,

Colorado Neurological Institute (CNI), United States

Mark Janssen,

Maastricht University Medical Centre, Netherlands

*Correspondence:

Mounia Rahmani

mouniarahmani4@gmail.com

Specialty section:

This article was submitted to

Neurodegeneration,

a section of the journal

Frontiers in Neurology

Received: 30 September 2017

Accepted: 14 June 2018

Published: 31 July 2018

Citation:

Rahmani M, Benabdeljili M,

Bellakhdar F, El Alaoui Faris M, Jiddane M, El Bayad K, Boutbib F, Razine R, Gana R, El Hassani MR,

El Fatemi N, Fikri M, Sanhaji S,

Tassine H, El Alaoui Balrhiti I,

El Hadri S, Ech-cherif Kettani $N$, El Abbadi N, Amor M, Moussaoui A, Semlali A, Aidi S, Ait Benhaddou EH,

Benomar A, Bouhouche A,

Yahyaoui M, El Khamlichi A

El Ouahabi A, El Maaqili R, Tibar $H$, Arkha Y, Melhaoui A, Benazzouz A and

Regragui W (2018) Deep Brain Stimulation in Moroccan Patients With Parkinson's Disease: The Experience of Neurology Department of Rabat.

Front. Neurol. 9:532.

doi: 10.3389/fneur.2018.00532
Mounia Rahmani ${ }^{1 *}$, Maria Benabdeljlil ${ }^{1}$, Fouad Bellakhdar ${ }^{2}$, Mustapha El Alaoui Faris ${ }^{1}$ Mohamed Jiddane ${ }^{3}$, Khalil El Bayad ${ }^{4}$, Fatima Boutbib ${ }^{1}$, Rachid Razine ${ }^{5}$, Rachid Gana ${ }^{2}$, Moulay R. El Hassani ${ }^{3}$, Nizar El Fatemi ${ }^{2}$, Meryem Fikri ${ }^{3}$, Siham Sanhaji ${ }^{1}$, Hennou Tassine ${ }^{4}$, Imane El Alaoui Balrhiti ${ }^{1}$, Souad El Hadri ${ }^{1}$, Najwa Ech-Cherif Kettani ${ }^{3}$, Najia El Abbadi ${ }^{2}$, Mourad Amor ${ }^{6}$, Abdelmjid Moussaoui ${ }^{6}$, Afifa Semlali ${ }^{7}$, Saadia Aidi ${ }^{1}$, El Hachmia Ait Benhaddou ${ }^{4}$, Ali Benomar ${ }^{4}$, Ahmed Bouhouche ${ }^{4}$, Mohamed Yahyaoui ${ }^{4}$,

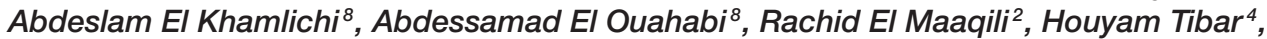
Yasser Arkha ${ }^{8}$, Adyl Melhaoui ${ }^{8}$, Abdelhamid Benazzouz ${ }^{9}$ and Wafa Regragui ${ }^{4}$

${ }^{1}$ Research Team in Neurology and Neurogenetics, Department of Neurology A and Neuropsychology, Faculty of Medicine and Pharmacy, Hôpital des Spécialités ONO, University Mohammed V, Rabat, Morocco, ${ }^{2}$ Department of Neurosurgery, Faculty of Medicine and Pharmacy, Hôpital Ibn Sina, University Mohammed V, Rabat, Morocco, ${ }^{3}$ Department of Neuroradiology, Faculty of Medicine and Pharmacy, Hôpital des Spécialités ONO, University Mohammed V, Rabat, Morocco, ${ }^{4}$ Research Team in Neurology and Neurogenetics, Department of Neurology B and Neurogenetics, Faculty of Medicine and Pharmacy, Hôpital des Spécialités ONO, University Mohammed V, Rabat, Morocco, ${ }^{5}$ Laboratory of Biostatistics, Clinical Research and Epidemiology, Faculty of Medicine and Pharmacy, University Mohammed V, Rabat, Morocco, ${ }^{6}$ Department of Anesthesia and Intensive Care, Faculty of Medicine and Pharmacy, Hôpital des Spécialités ONO, University Mohammed V, Rabat, Morocco, ${ }^{7}$ Department of Surgical Intensive Care, Faculty of Medicine and Pharmacy, Hôpital Ibn Sina, University Mohammed V, Rabat, Morocco, ${ }^{8}$ Department of Neurosurgery, Faculty of Medicine and Pharmacy, Centre de Rehabilitation et de Neurosciences, Hôpital des Spécialités ONO, University Mohammed V, Rabat, Morocco, ${ }^{9}$ Centre National de la Recherche Scientifique, Institut des Maladies Neurodégénératives, Univ. de Bordeaux UMR 5293, Bordeaux, France

Introduction: Deep brain stimulation (DBS) of the subthalamic nucleus (STN) is known as a therapy of choice of advanced Parkinson's disease. The present study aimed to assess the beneficial and side effects of STN DBS in Moroccan Parkinsonian patients.

Material and Methods: Thirty five patients underwent bilateral STN DBS from 2008 to 2016 in the Rabat University Hospital. Patients were assessed preoperatively and followed up for 6 to 12 months using the Unified Parkinson's Disease Rating Scale in four conditions (stimulation OFF and ON and medication OFF and ON), the levodopa-equivalent daily dose (LEDD), dyskinesia and fluctuation scores and PDQ39 scale for quality of life (QOL). Postoperative side effects were also recorded.

Results: The mean age at disease onset was $42.31 \pm 7.29$ years [28-58] and the mean age at surgery was $54.66 \pm 8.51$ years [34-70]. The median disease duration was 11.95 \pm 4.28 years [5-22]. Sixty-three percentage of patients were male. $11.4 \%$ of patients were tremor dominant while 45.71 showed akinetic-rigid form and 42.90 were classified as mixed phenotype. The LEDD before surgery was 1200 mg/day [800-1500]. All patients had motor fluctuations whereas non-motor fluctuations were present in $61.80 \%$ of cases. STN DBS decreased the LEDD by $51.72 \%$, as the mean LEDD post-surgery was 450 [188-800]. The UPDRS-III was improved by $52.27 \%$, dyskinesia score by $66.70 \%$ and motor fluctuations by $50 \%$, whereas QOL improved by $27.12 \%$. Post-operative side effects were hypophonia (2 cases), infection (3 cases), and pneumocephalus (2 cases). 
Conclusion: Our results showed that STN DBS is an effective treatment in Moroccan Parkinsonian patients leading to a major improvement of the most disabling symptoms (dyskinesia, motor fluctuation) and a better QOL.

Keywords: Parkinson disease, deep brain stimulation, subthalamic nucleus, quality of life, surgical benefit, clinical outcome

\section{INTRODUCTION}

Stereotactic surgery represents a highly effective therapy for the treatment of Parkinson's disease (PD) and other movement disorders refractory to medical treatment. The use of deep brain stimulation (DBS) for PD was driven by advances in the understanding of the pathophysiology and availability of animal models of the disease. In 1993, Benazzouz et al. (1) successfully performed high frequency stimulation of the subthalamic nucleus (STN) in Macaca mulatta monkeys rendered parkinsonian by MPTP (1-methyl-4phenyl1,2,3,6-tetrahydropyridine). The authors have reported dramatic improvements of the motor symptoms without the development of abnormal involuntary movements. In 1994, Benabid et al. (2) and Siegfried and Lippitz (3) reported successful treatment of patients with PD who underwent DBS of the subthalamic nucleus (STN) and of the globus pallidus internus (GPi), respectively. The procedure is now commonly used in patients with intractable tremor, or with disabling drug-induced complications, especially motor fluctuations and/or dyskinesia. DBS in its current form is a symptomatic treatment that does not interfere with the progression of the disease, and does not affect the non-levodopa responsive motor and non-motor aspects of the disorder such as levodopa-refractory freezing of gait and balance problems nor non-motor aspects of the disease (4).

Nowadays, the STN is widely considered the target of choice (5-8). The mechanism of the stimulation effect on PD is not fully understood but thought to likely be related to the modulation of neuronal activity and the reinstatement of balance within basal ganglia connections $(4,9,10)$. The postoperative clinical outcome depends on the quality of the inclusion clinical criteria and the precision of targeting for electrode implantation, which is based on neuroimaging techniques, intraoperative electrophysiology and test of the stimulation effects $(11,12)$.

Multiple series have reported on the long-term efficacy of DBS for PD (13-23). Here we report our experience of STN DBS performed in a cohort of Moroccan PD patients over a period of 9 years. We describe our results of this first Moroccan series, with a particular emphasis on evaluating the effectiveness and safety of this neurosurgical treatment on the first year of follow up.

\section{MATERIALS AND METHODS}

We conducted a retrospective study of 35 patients with advanced PD who underwent bilateral STN DBS surgery from January 2008 to December 2016 in the University Hospital of Rabat. Surgery was performed in two different departments of neurosurgery, using the same technical procedure. The study was approved by ethics committee of medical school of Rabat and all patients provided their written informed consent.

\section{Patient's Selection}

Evaluations were performed by neurologists specialized in movement disorders. Inclusion criteria for pre-operative assessment were diagnosis of PD according to the UK Brain Bank Criteria (24), age under 70 years old, severe parkinsonian motor symptoms or dyskinesia that limit activities of daily living despite optimal medical therapy for at least 6 months, no dementia or major general illness. A systematic psychiatric appraisal was made to assess and treat any severe depression.

All patients underwent a pre-operative testing. Levodopa challenge was analyzed, and an improvement of at least $30 \%$ was necessary to confirm levodopa responsiveness. A morphologic MRI was performed to exclude patients with severe cerebral atrophy, ischemic lesions or other brain injuries that may contra-indicate the surgical procedure. All subjects had also a neuropsychological testing. Global cognitive functioning was evaluated by the Mattis Dementia Rating Scales (MDRS) (25, 26) and the Montreal Cognitive Assessment (MoCA) $(26,27)$, intellectual capacities by the Progressive Matrices de Raven (PM47) $(26,28)$, executive functions by the Trail Making Test (TMT), Stroop test and Frontal Assessment Battery (FAB), memory by the verbal fluency and the Memory Impairment Screen (MIS-D), visual and constructive abilities by the Rey figure and the Benton Visual Retention Test (26). We considered a score of MDRS lower than 130/144 a cut off for DBS eligibility as well as severe executive troubles. Patients were eligible for surgery if they responded to levodopa, challenge with normal brain MRI, normal cognitive tests, and no major drug-resistant depression.

\section{Pre-operative Evaluation}

All patients were assessed using a form that specifies the demographic characteristics (age, gender, age of onset, duration of the disease), clinical features [laterality of symptoms, predominant features: tremulous, akinetic-rigid, or mixed subtypes according to criteria used in 2008 by Rajput et al. (29)], disease severity assessed by the motor section of the UPDRS score (Unified Parkinson's Disease Rating Scale) and Hoehn and Yahr scale (24), motor complications [fluctuations, dyskinesia, freezing of gait (FOG)] and non-motor fluctuations (dysautonomic troubles, sleep disorders, depression, cognitive disturbances, hallucinations, delirium), Levodopa Equivalent Daily Doses (LEDD) calculated based on a previously published algorithm combining dopamine agonist daily dose with levodopa daily dose (30),UPDRS I for mental cognitive assessment, UPDRS II and Schwab and England Scale for activity of daily living (ADL), Giovannoni criteria (31) for 
dopamine dysregulation syndrome (DDS), Montgomery-Asberg Depression Scale (MADRS) and Hamilton anxiety rating scale (HAM-A) to evaluate mood disorder and PDQ 39 for quality of life (32).

\section{Surgical Targeting and Procedure}

A Leksell G stereotactic frame (Elekta $A B$ ) was placed under local anesthesia. We performed a preoperative 1.5 Tesla cerebral MRI with the following sequences: ventriculographic CISS (constructive interference in steady state), MPR (Multi-plan Reconstruction) with gadolinium, and coronal T2 DESS (double echo steady state) followed by a CT scan to check for any MRI-generated distortion. All the images were transferred to the surgical planning station (Elekta Surgiplan*). The STN coordinates were calculated using direct (based on MRI T2 DESS) and indirect (using statistical coordinates) methods $(33,34)$.

The first operated side was the one contralateral to the most impaired body-side. The electrodes were implanted in a single operative session under local anesthesia and the target was identified by a combination of neuroimaging, microelectrode recording, and stimulation tests. For each patient, trajectories were determined on the basis of individual anatomical variations and stereotactic MRI based software was used to plan an optimal trajectory from the defined entry point to the sensorimotor STN stimulation target (anatomically referred to as dorso-lateral STN) by avoiding critical brain structures.

The STN stimulation target was defined using a combination of statistical coordinates of STN (4 mm inferior, 3.9 posterior, and $12 \mathrm{~mm}$ lateral from midcomissural point), and direct visualization on MRI where the STN was chosen at the anterior margin of red nucleus and 2 to $3 \mathrm{~mm}$ lateral from its external border.

Stereotactic gadolinium enhanced T1-weighted images were used to visualize vessels to avoid injury of any vascular structure during surgery.

All trajectories were anterior to the motor strip close to the coronal suture on sagittal plane, and about 2 to $3 \mathrm{~cm}$ from midline in coronal plane. The final trajectory was defined as to get a maximum of definitive electrode plots within the visualized hypointensity of STN. To reach this, the trajectory direction should superimpose to the vertical axis of the STN.

Multi-track (3-5) microelectrodes were inserted for electrophysiological mapping of the STN. Subsequent macrostimulations were used to assess the efficacy and side effect profile of the tested electrodes. The optimal track (best micro-recording and widen therapeutic window on macro-stimulation) was chosen for each side and the permanent quadripolar leads were implanted (model 3389; Medtronic, Minneapolis, Minn., USA). Continuous fluoroscopy was used to monitor a potential electrode displacement and to confirm the definitive electrode positioning. Non-absorbable silk stich was used to anchor the definitive electrode and the burr hole was sealed by acrylic cement. The mean surgery duration was $5-7 \mathrm{~h}$ from the scalp incision.

Post-operative CT scan was performed immediately after surgery to rule out surgical complications such as hemorrhage and to confirm the final location of the implanted electrodes based on fusion of the preoperative MRI and postoperative CT scan images. The internal pulse generators (model 7428 Kinetra, or 37601 Activa PC; Medtronic) were implanted the same day or 3-5 days later in a subcutaneous pocket in the infra-clavicular region under general anesthesia.

\section{Stimulation Programming}

The 8 lead contacts were assessed 1-3 months after surgery when the lesion-like effect responsible of spontaneous postoperative improvement of PD symptoms, has disappeared. The best contact that improved the symptoms without side effects was chosen for each side.

\section{Post-operative Evaluation}

Patients were evaluated 6-12 months after surgery using section III of the UPDRS in four conditions (stimulation OFF and ON and medication OFF and ON). Subscales of UPDRS III were assessed as follow: speech score expresses item 18, tremor is the sum of items 20 , and 21 , rigidity is item 22 , bradykinesia is the sum of items 23 to 27,30 , and 31 , posture is item 28 and postural instability item 29. Patients were also assessed for the LEDD, dyskinesia score (the sum of items $32-35$ of the UPDRS IV), motor fluctuations score (the sum of items 36-39 of the UPDRS IV), MADRS, HAM-A and PDQ39 scale expressed as summary index (SI) that ranges between 0 and $100 \%$ (100\% is equivalent to bad quality of life) and as its eight dimensions (35). Postoperative side effects were also recorded.

\section{Statistical Analysis}

SPSS 13.0 software was used for the statistical processing of our data. Quantitative data were expressed in mean \pm standard deviation $(S D)$ or median and interquartile range. Categorical variables were expressed as numbers and percentages. Data were tested for normal distribution by graphical methods. Pre and post intervention quantitative variables of normal distribution were compared using paired-t test (UPDRS III, Dyskinesia scores, Motor Fluctuations scores, PDQ39 SI, Bradykinesia subscale of UPDRS III) and pre and post intervention quantitative variables of non normal distribution (UPDRS I, UPDRS II, LEDD, PDQ 39 subscales, speech, tremor, rigidity, posture, and postural instability subscales of UPDRS III) and ordinal variables (UPDRS $\mathrm{V}$ and VI) were analyzed using Wilcoxon test. Pre and post intervention categorical data were compared using McNemar test. Statistical significance was assumed for tests yielding $p$ values of less than 0.05 .

\section{RESULTS}

\section{Demographic Data}

The mean age at disease onset was $42.31 \pm 7.29$ years and the mean age at surgery was $54.66 \pm 8.51$ years. The median disease duration was $11.95 \pm 4.28$ years. Sixty-three percentage of patients were male. Four patients were tremor-dominant, 16 patients showed an akinetic rigid form and 15 patients were classified as mixed subtype. The LEDD before surgery was $1200 \mathrm{mg} /$ day [800-1500]. Mean time to appearance of motor fluctuations was $7.81 \pm 4.25$ years [1-16], non-motor fluctuations $8.05 \pm 3.34$ years $[2-15]$ and dyskinesia $7.82 \pm 3.76$ years [214]. The most disabling symptom was akinetic state (40\%) 
TABLE 1 | Baseline characteristics of the study population $(n=35)$.

\begin{tabular}{ll}
\hline Clinical data & Figures \\
\hline Age at onset & $42.31 \pm 7.29[28-58]^{\star \star}$ \\
Age at surgery & $54.65 \pm 8.51[34-70]^{\star *}$ \\
Sex (M) & $62.90(22)^{\star}$ \\
Disease duration & $11.97 \pm 4.28[5-22]^{\star *}$ \\
Motor phenotype & \\
Akinetic-rigid & $45.70(16)^{\star}$ \\
Tremoric & $11.40(4)^{\star}$ \\
Mixed & $42.90(15)^{\star}$ \\
Motor complications & \\
Motor fluctuations & $100(35)^{\star}$ \\
Dyskinesia & $85.71(30)^{\star}$ \\
Freezing of gait & $28.57(10)^{\star}$ \\
Non-motor fluctuations & $61.80(21)^{\star}$ \\
Most disabling symptoms & \\
Akinesia & $40.00(14)^{\star}$ \\
Dyskinesia & $20.00(7)^{\star}$ \\
Akinesia and dyskinesia & $34.28(12)^{\star}$ \\
Tremor and dyskinesia & $2.85(1)^{\star}$ \\
DDS & $34.28(12)^{\star}$ \\
LEDD & $1200[800-1500]^{\star \star *}$ \\
\hline
\end{tabular}

"Percentage (number), "Means and standard deviation [minimum, maximum], "** Median and interquartile range, $M$, males; $D D S$, dopamine dysregulation syndrome; $L E D D$, levodopa equivalent daily doses.

followed by akinesia and dyskinesia in the same time $(34.21 \%)$ then dyskinesia alone (7\%). Only one patient suffered from disabling tremor associated with dyskinesia. More than one third of patients presented a dopamine dysregulation syndrome (Table 1).

\section{Surgery Related Complications}

Some side effects were recorded during or immediately after surgery. They were mild and transient: confusional episode (2 cases), hallucination (1 case), hypophonia (1 case), aphonia (1 case), anxiety (2 cases), hypomania (1 case), and pneumocephalus ( 2 cases).

\section{DBS Related Complications}

Long term complications were as follow: two patients suffered from dysarthria that needed changes of stimulation parameters, three patients presented direct hardware-related complications; two patients exhibited a battery site infection 3 and 5 months after surgery that was resolved after antibiotic treatment for one patient and after removal of the battery and the lead for the other one. Another subject experienced, 6 months after surgery, an infection of the lead/wire connection site. The whole DBS system was removed then repositioned 8 months later. One patient had unilateral misplacement of the lead with a medial deviation of $3.2 \mathrm{~mm}$. Following a reimplantation of the lead, the patient presented clinical improvement and the CT scan showed correct positioning of the lead.

\section{Changes in Motor Outcome}

Comparison between pre-and postoperative clinical state is summarized in Table 2. There is no change in the part II of the UPDRS following surgery except for a tendency to a small improvement in activity of daily living during OFF medication state up to $10 \%$ but without reaching significance ( $p$ $=0.06)$.

There is a significant improvement of the UPDRS III especially when patients were in OFF state with a rate of $52.25 \%$. Motor fluctuation scores were improved by $50 \%$ and dyskinesia score by more than $66 \%$. There was no more OFF FOG after surgery. The England and Schwab score in OFF medication was also improved by $36.66 \%$. LEDD was decreased up to $51.72 \%$.

UPDRS III subscales analysis in the four conditions, medication $\mathrm{OFF}$ and $\mathrm{ON}$ with and without stimulation, showed that tremor, rigidity, and bradykinesia scores were significantly improved by STN DBS in both medication OFF and ON states. Posture was improved only in medication OFF state and there was no modification in speech and postural instability by stimulation. The whole UPDRS III score was improved by $50 \%$ or more in medication OFF and ON states (Table 3).

\section{Changes in Quality of Life and Non-motor Outcome}

There was no modification in UPDRS part I, depression, anxiety scores or in the prevalence of the DDS. The quality of life (PDQ39 SI) was improved by $27 \%$. We also assessed the subscales of PDQ-39 score. The only improved dimensions were mobility ( $p$ $=0.004)$, ADL $(p=0.003)$, and Sigma $(p=0.038)$. The others, mainly emotional well-being $(p=0.166)$, social support $(p=$ $0.806)$, cognition $(p=0.954)$, communication $(p=0.747)$, and bodily discomfort $(p=0.281)$ were not improved.

\section{Post-operative DBS Setting}

As shown in Table 4, contact $3(37.35 \%)$ was chosen most often for permanent stimulation followed by contact $2(34.94 \%)$ and contact $1(18.07 \%)$. Contact 0 was rarely selected $(9.63 \%)$. Contact 0 refers to the most ventral contact and contact 3 to the most dorsal one. The mean proportion of patients who needed bipolar stimulation was $11.42 \%$ whereas $12.85 \%$ needed two active contacts. The stimulation parameters (mean \pm SD) were $2.82 \pm 0.57 \mathrm{~V}, 163.29 \pm 35.79 \mathrm{~Hz}$ and $65.67 \pm 11.91 \mu \mathrm{s}$ (2 patients had $60 \mu$ s at one side and $90 \mu$ s at the other).

\section{DISCUSSION}

STN-DBS efficacy on PD motor symptoms is well documented in the short and medium terms, up to 5 years $[(13)-(23,36,37)]$, while a few publications with a small number of examined patients addressed the long-term efficacy of this procedure (3841). Here, we report the one-year outcome of a cohort of 35 consecutive PD patients at advanced stage of the disease, who underwent bilateral STN-DBS.

The age at surgery of 54 years was in line with a Canadian series (38) but much lower than larger series where patients 
TABLE 2 | Comparison of pre and post-operative clinical state (stimulation ON).

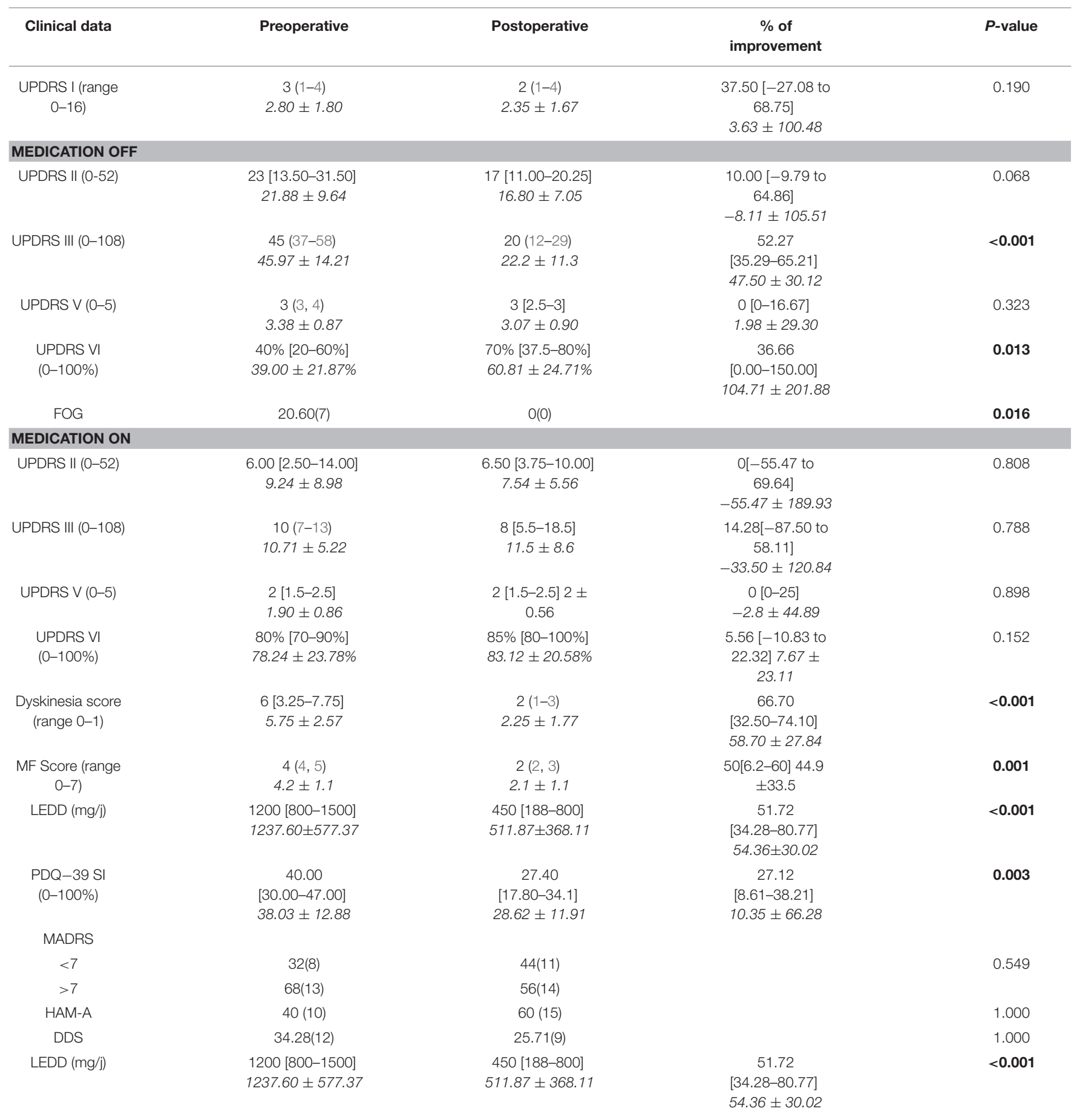

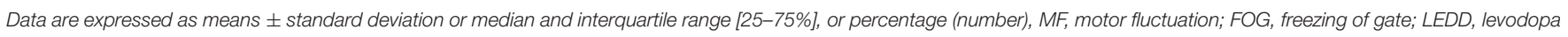

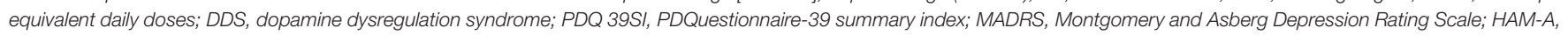
Hamilton anxiety scale. Bold values refer to significant $p$ value.

were operated between $58-61$ years of age $(36,37,42)$. This can be explained by the young age of onsetalready reported in our population with an age of onset $<55$ years in $45 \%$ and $<45$ years in $15 \%$ (43). The disease duration of $11.97 \pm$ 4.28 years was similar to other series $[1516,22,23,36-39$,
$42,44]$. The usefulness of DBS in early stage of the disease is currently a subject of debate. Results of the EarlyStim Trial (45) demonstrated that DBS was superior to medical therapy with respect to motor disability, activities of daily living, levodopainduced motor complications and time with good mobility and 
TABLE 3 | Effects of STN DBS on UPDRS III subscales.

\begin{tabular}{|c|c|c|c|c|c|c|}
\hline Scores & \multicolumn{3}{|c|}{ Medication OFF } & \multicolumn{3}{|c|}{ Medication ON } \\
\hline $\begin{array}{c}\text { Tremor (items } \\
20+21 \text { ) }\end{array}$ & $\begin{array}{c}3[0-5] \\
3.64 \pm 4.41\end{array}$ & $\begin{array}{c}0[0-2.5] \\
1.32 \pm 1.70\end{array}$ & 0.001 & $\begin{array}{c}0[0-3] \\
1.74 \pm 3.25\end{array}$ & $\begin{array}{c}0[0-1] \\
0.83 \pm 1.66\end{array}$ & 0.018 \\
\hline $\begin{array}{l}\text { Bradykinesia (sum } \\
\text { of items } \\
23-27+30+31 \text { ) }\end{array}$ & $\begin{array}{c}24[16.5-32.5] \\
23.80 \pm 9.32\end{array}$ & $\begin{array}{c}11(8-19) \\
13.12 \pm 6.56\end{array}$ & $<0.001$ & $\begin{array}{c}8(5-21) \\
12.70 \pm 10.95\end{array}$ & $\begin{array}{c}4.5(3-8) \\
6.00 \pm 5.33\end{array}$ & $<0.001$ \\
\hline Posture (item 28) & $\begin{array}{c}1[0-1] \\
0.80 \pm 0.76\end{array}$ & $\begin{array}{c}1[0-1] \\
0.48 \pm 0.59\end{array}$ & 0.005 & $\begin{array}{c}0[0-0] \\
0.26 \pm 0.54\end{array}$ & $\begin{array}{c}0[0-0] \\
0.13 \pm 0.34\end{array}$ & 0.083 \\
\hline $\begin{array}{l}\text { Postural instability } \\
\quad \text { (item 29) }\end{array}$ & $\begin{array}{c}2(1,2) \\
1.75 \pm 1.03\end{array}$ & $\begin{array}{c}1(1,2)^{\star \star} 1.40 \pm \\
1.04^{\star}\end{array}$ & 0.109 & $\begin{array}{c}2(1,2) \\
1.48 \pm 1.12\end{array}$ & $\begin{array}{c}1[0-2] \\
1.08 \pm 1.06\end{array}$ & 0.159 \\
\hline
\end{tabular}

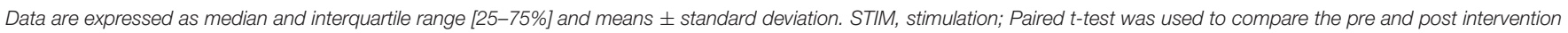
means of UPDRS III, Bradykinesia subscale of UPDRS III. Wilcoxon test was used for the other subscores. Bold values refer to significant $p$ value. Bold values refer to significant $p$ value.

TABLE 4 | Electrode contact chosen for permanent stimulation (35 patients).

\begin{tabular}{lccc}
\hline Contacts & Right STN & Left STN & TOTAL (83) \\
\hline 0 & 4 & 4 & $8(9.63 \%)$ \\
1 & 6 & 9 & $15(18.07 \%)$ \\
2 & 15 & 14 & $29(34.94 \%)$ \\
3 & 14 & 17 & $31(37.35 \%)$ \\
\hline
\end{tabular}

Data are given as numbers (\%). thirteen electrodes were employed for double monopolar contact stimulation and eight electrodes for bipolar stimulation. Contact 0 refers to the most ventral contact and contact 3 the most dorsal one. STN, subthalamic nucleus.

no dyskinesia. However, the poor access of our population to DBS surgery makes the question quite obsolete, as we are in the obligation to offer this therapeutic option to really disabled patients.

When compared to baseline, STN DBS in our patients allowed a major benefit in different components of motor function as widely noted in different series (46). It improved the UPDRS III score and the cardinal symptoms both in OFF and ON medication conditions. These results attest two points: (i) the superiority of DBS in relieving these symptoms as patients had better scores in $\mathrm{ON}$ medication/ON stimulation than in ON medication/OFF stimulation and (ii) the best motor state in the morning before taking their first dose of dopaminergic drugs (OFF medication/ON stimulation). Moreover, effective contacts were the most dorsal ones (contacts 2 and 3). This result may be explained by the phenotype of our patients (11.40\% tremor dominant and 42.71 mixed forms) requiring current diffusion to zona incerta to relieve severe tremor (47).

In addition, STN DBS is equivalent to dopamine effect on the posture by means of rigidity relief. As expected, surgery did not ameliorate both postural instability and dysarthria. Indeed, the effect of stimulation on axial symptoms is known to be poor, their pathophysiology being different $(46,48-51)$. Moreover, patients can even exhibit a slight deterioration in axial symptoms, which is associated with the progression and the natural evolution of the disease $(38-41,46)$. An older age, intensity of axial symptoms and UDPRS II off-medication score (items 5-17) before surgery were predictive factors of dysarthria/hypophonia and postural instability after surgery (44). In our patients, the young age at surgery may explain in part the absence of such side effects. Otherwise, there was no more medication OFF FOG postoperatively confirming the benefit of DBS on dopa-sensitive symptoms.

Subsequently, we observed a considerable reduction in the daily doses of antiparkinsonian medication, up to $50 \%$ of the preoperative doses, which participated in the antidyskinetic effect of DBS. Indeed, we recorded a major reduction in dyskinesia by $66.70 \%$ and in the frequency and severity of motor fluctuations by $50 \%$, both are known to significantly contribute to preoperative functional limitations (46) and considered by our patients as the most disabling symptoms. These results are in line with most series that reported a reduction of medication doses of 19 to $80.7 \%$, motor fluctuation scores of 16 to $95 \%$ and dyskinesia scores of $53-92 \%(16,22,37,42,52-60)$.

There was a limited advantage of surgery on ADL assessed by UPDRS II in OFF medication state with just a trend to improvement and no effect in $\mathrm{ON}$ state for our patients. In several series, ADL in On medication condition had not improved or even declined at 1 year and remained stable at 5 years despite reductions in dyskinesia duration and severity, whereas in OFF medication, ADL improved by 49 to $54.2 \% 5$ years after surgery $(16,36,37,42,61,62)$. However, in our series, when ADL was measured using the Schwab and England scale, we observed a significant improvement of ADL in OFF medication by $36.66 \%$, which was in line with most series $(16,36,37)$. 
The good effect of STN DBS was also attested by an overall improvement of quality of life by $27 \%$ in our patients assessed by the PDQ-39 SI. This rate is in contrast with the dramatic improvement of the motor function especially the most disabling symptoms (dyskinesia and motor fluctuations) but is in agreement with previous studies. Indeed, the improvement of QOL reported varied from 30.2 to $50.6 \%(63,64)$. Dimensions affected by DBS are subject of conflict. Some authors report that DBS ameliorates all dimensions of QOL, whereas others emphasize that the dimensions improved are those that surgery is expected to affect ( $\mathrm{ADL}$ and mobility) but not the others (social support, cognition, and communication) (23, 64-66). Sobstyl et al. (66) demonstrated a correlation between dyskinesia and the improvement of "Mobility" and "ADL" dimensions and PDQ39 SI. This correlation can explain our results, as the significantly improved dimensions were "Mobility," "ADL," and "Stigma." The improvement of "Stigma" dimension may result from the impact of dyskinesia on social life especially in our country where hyperkinetic movements are culturally not appreciated. The disappearance of dyskinesia allowed patients to be involved in social life. Over all, further studies on a large number of patients and long follow up are needed to determine the impact of DBS on QOL taking into account both motor and non-motor symptoms. The moderate improvement of QOL by STN DBS reported up to now highlights the major influence of nonmotor symptoms on quality of life (67, 68).

Various studies found no effect of STN DBS on cognitive functions while others noted worsening of verbal fluency or transient cognitive impairments $(56,69-72)$. In our series, we did not observe any change in cognitive and mood scales. Patients with preexisting cognitive impairment were not selected for DBS. On the other hand, all subjects were screened for depression and psychiatric disorders in order to avoid the reported potential exacerbation of mood disorders after surgery $(34,71-74)$.

DDS is one of the clinical aspects of Impulse Control Behaviors (ICB). It has a prevalence of $13.6 \%$ in PD and may be considered as the neuropsychiatric equivalent of levodopainduced dyskinesia (75-77). Contrasting results of DBS on ICB are reported in the literature (78-83). Merola et al. (84) in their study of 150 consecutive PD STN-DBS-treated patients, reported only an overall trend for reduction of ICB but with significant improvement in hypersexuality, gambling and DDS after a follow up of $4.3 \pm 2.1$ years. In our series, there was no modification in the prevalence of DDS after surgery. Patients were assessed 6 to 12 months after surgery, which could be considered insufficient to appreciate the modification of their ICB. Nevertheless, new ICB may occur in some subjects with risk factors such as: younger age, female, lower dyskinesia improvement and schizoid traits of personality disorders (84). A longer follow up is needed to assess our patients for new ICB.

STN DBS can be regarded as a safe procedure in properly selected patients. Mortality and permanent morbidity are very low and surgical complications are relatively rare. However, numerous surgical, hardware-related, or infective complications may be developed after surgery or during the follow-up period, sometimes even years after the intervention for lead positioning (85). The rates of these complications are quite variable in the literature and include intracranial hemorrhage (0-10\%), stroke $(0-2 \%)$, infection $(0-15 \%)$, lead erosion without infection (1$2.5 \%)$, lead fracture (0-15\%), lead migration (0-19\%), and death $(0-4.4 \%)(13,85-89)$. In our series, we did not record any cerebral hemorrhage. Major complications included infections and hardware-related ones, occurring in $8.6 \%$ of cases.

Psychiatric disorders were seen during surgery in 6 patients. This difficulty to complete the surgical procedure has been recently reported by other groups as a factor that can be time wasting and frustrating for both the patient and the surgeon, observed mainly in early series. The most frequent cause is a psychiatric disturbance of the patient, with hallucinations and impossibility to cooperate during surgery (85, 90-94).

\section{CONCLUSION}

Our results showed that STN DBS is an effective treatment in Moroccan Parkinsonian patients leading to a major improvement of the most disabling symptoms (dyskinesia, motor fluctuation) and a better QOL. These findings, which are in line with those previously reported in other caucasian and asian population, showed that in carefully selected Moroccan patients with a multidisciplinary management, STN DBS is a powerful treatment that alleviates the burden of advanced PD.

\section{AUTHOR CONTRIBUTIONS}

MR and WR participated equally to the design of the study, edited the manuscript, participated in patients' selection, peroperative microrecording, and macrostimulation testing and programming. FoB, YA, and AdM performed lead targeting and surgery. RG, NEF, and NEA: participated in surgery. MJ, MoE, MF, and NEK performed acquisition, analysis, and interpretation of radiological data. $\mathrm{FaB}$ and $\mathrm{SS}$ performed neuropsychological assessment. AbM, MA, and AS performed anesthetic monitoring. MB participated in patient's selection, peroperative neurophysiology, and macrostimulation testing. MEF participated in patients' selection and gave agreement for clinical data. SE, HeT, IEB, and HoT participated in collecting data. KE performed and edited statistical analysis. RR supervised statistical analysis. AbB participated in per-operative neurophysiology and revising the manuscript. $\mathrm{AhB}$ and $\mathrm{EAB}$ participated in critical reading of the manuscript. $S A, A l B$, and $M Y$ gave agreement for clinical data. AEK, AEO, FoB, and RE gave agreement for surgical data.

\section{ACKNOWLEDGMENTS}

We are very grateful to Janardan Vaidynathan, $\mathrm{PhD}$, for his support in the surgical procedure and electrophysiology recording. We are also thankful to Dr. Kaswati Janane for his help on statistics. 


\section{REFERENCES}

1. Benazzouz A, Gross C, Feger J, Boraud T, Bioulac B. Reversal of rigidity and improvement in motor performance by subthalamic high frequency stimulation in MPTP-treated monkeys. Eur J Neurosci. (1993) 5:382-89. doi: 10.1111/j.1460-9568.1993.tb00505.x

2. Benabid AL, Pollak P, Gross C, Hoffmann D, Benazzouz A, Gao DM, et al. Acute and long-term effects of subthalamic nucleus stimulation in Parkinson's disease. Stereotact Funct Neurosurg. (1994) 62:76-84. doi: 10.1159/000098600

3. Siegfried J, Lippitz B. Bilateral continuous electrostimulation of ventropostero lateral pallidum: a new therapeutic approach for alleviating all Parkinsonian symptoms. Neurosurgery (1994) 35:1126-30. doi: 10.1227/00006123-199412000-00016

4. Wichmann T, DeLong MR. Deep-brain stimulation for basal ganglia disorders. Basal Ganglia (2011) 1:65-77. doi: 10.1016/j.baga.2011.05.001

5. Limousin P, Krack P, Pollak P, Benazzouz A, Ardouin C, Hoffmann $D$, et al. Electrical stimulation of the subthalamic nucleus in advanced Parkinson's disease. N Engl J Med. (1998) 339:1105-11. doi: 10.1056/NEJM199810153391603

6. Limousin P, Martinez-Torres I. Deep brain stimulation for Parkinson's disease. Neurotherapeutics. (2008) 5:309-19. doi: 10.1016/j.nurt.2008.01.006

7. Benabid AL, Chabardes S, Mitrofanis J, Pollak, P. Deep brain stimulation of the subthalamic nucleus for the treatment of Parkinson's disease. Lancet Neurol. (2009) 8:67-81. doi: 10.1016/S1474-4422(08) 70291-6

8. Odekerken VJJ, Van Laar T, Staal MJ, Mosch A, Hoffmann CFE, Nijssen PCG, et al. Subthalamic nucleus versus globus pallidus bilateral deep brain stimulation for advanced Parkinson's disease (NSTAPS study): a randomised controlled trial. Lancet Neurol. (2013) 12:37-44. doi: 10.1016/S1474-4422(12)70264-8

9. Benazzouz A, Hallett M. Mechanism of action of deep brain stimulation. Neurology (2000) 55(12 Suppl. 6):S13-6.

10. DaCunha C, Boschena SL, Gómez A-A, Ross EK, Gibson WSJ, Min HK, et al. Toward sophisticated basal ganglia neuromodulation: review on basal ganglia deep brain stimulation. Neurosci Biobehav Rev. (2015) 58:186-210. doi: 10.1016/j.neubiorev.2015.02.003

11. Welter ML, Houeto JL, Tezenas du Montcel S, Mesnage V, Bonnet AM, Pillon B, et al. Clinical predictive factors of subthalamic stimulation in Parkinson's disease. Brain (2002) 125:575-83.

12. Bour Lo J, Fiorella Contarino M, Foncke EMJ, De Bie RMA, Van Den Munckhof P, Speelman JD, et al. Long-term experience with intraoperative microrecording during DBS neurosurgery in STN and GPi. Acta Neurochir. (2010) 152:2069-77. doi: 10.1007/s00701-010-0835-y

13. Deuschl G, Schade-Brittinger C, Krack P, Volkmann J, Schäfer H, Bötzel $\mathrm{K}$, et al. German Parkinson Study Group, Neurostimulation SectionA randomized trial of deep brain stimulation for Parkinsons's disease. $N$ Engl J Med. (2006) 355:896-908. doi: 10.1056/NEJMoa060281

14. Kleiner-Fisman G, Fisman DN, Sime E, Saint-Cyr JA, Lozano AM, Lang AE. Long-term follow-up of bilateral deep brain stimulation of the subthalamic nucleus in patients with advanced Parkinson's disease. J Neurosurg. (2003) 99:489-95. doi: 10.3171/jns.2003.99.3.0489

15. Follett KA, Weaver FM, Stern M, Hur K, Harris CL, Luo P, et al. Pallidal versus subthalamic deep-brain stimulation for Parkinson's disease. N Engl J Med. (2010) 362:2077-91. doi: 10.1056/NEJMoa09 07083

16. Krack P, Batir A, Van BN, Chabardes S, Fraix V, Ardouin C, et al. Five-year follow-up of bilateral stimulation of the subthalamic nucleus in advanced Parkinson's disease. N Engl J Med. (2003) 349:1925-34. doi: 10.1056/NEJMoa035275

17. Chan AYY, Yeung JHM, Mok VCT, Ip VHL, Wong A, Chan DTM, et al. Movement Disorder Group, Prince of Wales Hospital, The Chinese University of Hong Kong. Subthalamic nucleus deep brain stimulation for Parkinson's disease: evidence for effectiveness and limitations from 12 years'experience. Hong Kong Med, J. (2014) 20:474-80. doi: 10.12809/hkmj144242

18. Okun MS, Gallo BV, Mandybur G, Jagid J, Foote KD, Revilla FJ, et al. SJM DBS Study Group. Subthalamic deep brain stimulation with a constantcurrent device in Parkinson's disease: an open-label randomized controlled trial. Lancet Neurol. (2012) 11:140-9. doi: 10.1016/S1474-4422(11)70308-8
19. Pahwa R, Wilkinson SB, Overman J, Lyons KE. Bilateral subthalamic stimulation with Parkinson's disease: long-term follow-up. J Neurosurg. (2003) 99:71-7. doi: 10.3171/jns.2003.99.1.0071

20. Schupbach WM, Chastan N, Welter ML, Houeto JL, Mesnage V, Bonnet $\mathrm{AM}$, et al. Stimulation of the subthalamic nucleus in Parkinson's disease: a 5 year follow up. J Neurol Neurosurg Psychiatry (2005) 76:1640-44. doi: 10.1136/jnnp.2005.063206

21. Rodriguez-Oroz MC, Obeso JA, Lang AE, Houeto JL, Pollak P, Rehncrona $\mathrm{S}$, et al. Bilateral deep brain stimulation in Parkinson's disease: a multicentre study with 4 years follow-up. Brain (2005) 128:2240-49. doi: 10.1093/brain/awh571

22. Wider C, Pollob C, Bloch J, Burkhard PR, Vingerhoets FJG. Longterm outcome of 50 consecutive Parkinson's disease patients treated with subthalamic deep brain stimulation.Parkinsonism Relat Disord. (2008) 14:114-19. doi: 10.1016/j.parkreldis.2007.06

23. Williams A, Gill S, Varma T, Jenkinson C, Quinn N, Mitchell R, et al. On behalf of the PD SURG Collaborative Group.Deep brain stimulation plus best medical therapy versus best medical therapy alone for advanced Parkinson's disease (PD SURG trial): a randomised, open-label trial. Lancet Neurol. (2010) 9:581-91. doi: 10.1016/S1474-4422(10)70093-4

24. Hughes AJ, Daniel SE, Kilford L, Lees AJ. Accuracy of clinical diagnosis of idiopathic Parkinson's disease: a clinicopathological study of 100 cases. $J$ Neurol Neurosurg Psychol. (1992) 55:181-4.

25. Matteau E, Dupré N, Langlois M, Provencher P, Simard M. Clinical validity of the Mattis dementia rating scale-2 in Parkinson disease with MCI and dementia. J Geriatr Psychiatry Neurol. (2012) 25:100-6. doi: $10.1177 / 0891988712445086$

26. Romann AJ, Dornelles S, De Liz Maineri N, De Mello Rieder CR, Rozenfeld Olchik M. Cognitive assessment instruments in Parkinson's disease patients undergoing deep brain stimulation. Dement Neuropsychol. (2012) 6:2-11. doi: 10.1590/S1980-57642012DN06010002

27. Nasreddine ZS, Phillips NA, Bédirian V, Charbonneau S, Whitehead V, Collin I, et al. The Montreal Cognitive Assessment, MoCA: a brief screening tool for mild cognitive impairment. J Am Geriatr Soc. (2005) 53:695-99. doi: $10.1111 / j .1532-5415.2005 .53221 . x$

28. Gasca-Salas C, Estanga A, Clavero P, Aguilar-Palacio I, González-Redondo R, Obeso JA, et al. Longitudinal assessment of the pattern of cognitive decline in non-demented patients with advanced Parkinson's disease. J Parkinsons Dis. (2014) 4:677-86. doi: 10.3233/JPD-140398

29. Rajput AH, Sitte H, Rajput A, Fenton ME, Pifl C, Hornykiewicz $\mathrm{O}$, et al. Globus pallidus dopamine and Parkinson motor subtypes: clinical and brain biochemical correlation. Neurology (2008) 70:1403-10. doi: 10.1212/01.wnl.0000285082.18969.3a

30. Tomlinson CL, Stowe R, Patel S, Rick C, Gray R, Clarke CE, et al. Systematic review of levodopa dose equivalency reporting in Parkinson's disease. Mov Disord. (2010) 25:2649-53. doi: 10.1002/mds.23429

31. Giovannoni G, O'Sullivan JD, Turner K, Manson AJ, Lees AJ. Hedonistic homeostatic dysregulation in patients with Parkinson's disease on dopamine replacement therapies. J Neurol Neurosurg Psychiatry (2000) 68:423-28. doi: 10.1136/jnnp.68.4.423

32. Peto V, Jenkinson C, Fitzpatrick R, Greenhall R. The development and validation of a short measure of functioning and well-being for individuals with Parkinson's disease. Qual Life Res. (1995) 4:241-48. doi: $10.1007 / \mathrm{BF} 02260863$

33. Slavin KV, Anderson GJ, Burchiel KJ. Comparison of three techniques for calculation of target coordinates in functional stereotactic procedures. Stereotact Funct Neurosurg. (1999) 72:192-5. doi: 10.1159/000029725

34. Bejjani BP, Dormont D, Pidoux B, Yelnik J, Damier P, Arnulf I, et al. Bilateral subthalamic stimulation for Parkinson's disease by using three-dimensional stereotactic magnetic resonance imaging and electrophysiological guidance. J. Neurosurg. (2000) 92:615-25. doi: 10.3171/jns.2000.92.4.0615

35. Jenkinson C, Fitzpatrick R, Peto V, Greenhall R, Hyman N. The Parkinson's Disease Questionnaire (PDQ-39): development and validation of a Parkinson's disease summary index score. Age Ageing (1997) 26:353-57.

36. Rabie A, Metman LV, Fakhry M, Eassa AYE, Fouad W, Shakal A, et al. Improvement of advanced Parkinson's Disease manifestations with deep brain stimulation of the subthalamic nucleus: a single institution experience. Brain Sci. (2016) 6:E58. doi: 10.3390/brainsci6040058 
37. Li, J, Zhang, Y, Li, Y. Long-term follow-up of bilateral subthalamic nucleus stimulation in Chinese Parkinson's disease patients. Br J Neurosurg. (2015) 29:329-33. doi: 10.3109/02688697.2014.997665

38. Castrioto A, Lozano AM, Poon YY, Lang AE, Fallis M, Moro E, et al. Tenyear outcome of subthalamic stimulation in Parkinson disease: a blinded evaluation. Arch Neurol. (2011) 68:1550-56. doi: 10.1001/archneurol.2011.182

39. Fasano A, Romito LM, Daniele A, Piano C, Zinno M, Bentivoglio AR, et al. Motor and cognitive outcome in patients with Parkinson's disease 8 years after subthalamic implants. Brain (2010) 133:2664-76. doi: 10.1093/brain/awq221

40. Rizzone MG, Fasano A, Daniele A, Zibetti M, Merola A, Rizzi L, et al. Longterm outcome of subthalamic nucleus DBS in Parkinson's disease: from the advanced phase towards the late stage of the disease. Parkinsonism Relat Disord. (2014) 20:376-81. doi: 10.1016/j.parkreldis.2014.01.012

41. Zibetti M, Merola A, Rizzi L, Ricchi V, Angrisano S, Azzaro C, et al. Beyond nine years of continuous subthalamic nucleus deep brain stimulation in Parkinson's disease. Mov Disord. (2011) 26:2327-34. doi: 10.1002/mds. 23903

42. Weaver FM, Follett KA, Stern M, Luo P, Harris CL, Hur K, et al. Randomized trial of deep brain stimulation for Parkinson disease: thirty six-month outcomes. Neurology (2012) 79:55-65. doi: 10.1212/WNL.0b013e31825dcdc1

43. Regragui W, Lachhab L, Razine R, Raissouni L, Rasmouni K, Imounan F, et al. Profile of idiopathic parkinson's disease in Moroccan patients. Int Arch Med. (2014) 7:10. doi: 10.1186/1755-7682-7-10

44. Guehl D, Cuny E, Benazzouz A, Rougierb A, Tison F, Machadoc S, et al. Side-effects of subthalamic stimulation in Parkinson's disease: clinical evolution and predictive factors. Eur J Neurol. (2006) 13:963-71. doi: 10.1111/j.1468-1331.2006.01405.x

45. Schuepbach WMM, Rau J, Knudsen K, Volkmann J, Krack P, Timmermann L, et al. Neurostimulation for Parkinson's disease with early motor complications. N Engl J Med. (2013) 368:610-22. doi: 10.1056/NEJMoa1205158

46. Faggiani E, Benazzouz A. Deep brain stimulation of the subthalamic nucleus in Parkinson's disease: from history to the interaction with the monoaminergic systems. Prog Neurobiol. (2017) 151:139-156. doi: $10.1016 /$ j.pneurobio.2016.07.003

47. Blomstedt P, Stenmark Persson R, Hariz GM, Linder J, Fredricks A, Häggström B, et al. Deep brain stimulation in the caudal zona incerta versus best medical treatment in patients with Parkinson's disease: a randomised blinded evaluation. J Neurol Neurosurg Psychiatry (2018) 89:710-6. doi: 10.1136/jnnp-2017-317219

48. Hamani C, Richter E, Schwalb JM, Lozano AM. Bilateral subthalamic nucleus stimulation for Parkinson's disease: a systematic review of the clinical literature. Neurosurgery (2005) 56:1313-21. doi: 10.1227/01.NEU.0000159714.28232.C4

49. Skodda S. Effect of deep brain stimulation on speech performance in Parkinson's Disease. Parkinson's Dis. (2012) 2012:850596. doi: $10.1155 / 2012 / 850596$

50. Tripoliti E, Zrinzo L, Martinez-Torres I, Frost E, Pinto S, Foltynie $\mathrm{T}$, et al. Effects of subthalamic stimulation on speech of consecutive patients with Parkinson disease. Neurology (2011) 1:80-86. doi: 10.1212/WNL.0b013e318203e7d0

51. Fasano A, Daniele A, Albanese A. Treatment of motor and non-motor features of Parkinson's disease with deep brain stimulation. Lancet Neurol. (2012) 11:429-42. doi: 10.1016/S1474-4422(12)70049-2

52. Ostergaard K, Sunde N, Dupont E. Effects of bilateral stimulation of the subthalamic nucleus in patients with severe Parkinson's disease and motor fluctuations. Mov Disord. (2002) 17:693-700. doi: 10.1002/mds.10188

53. Vesper J, Klostermann F, Stockhammer F, Funk T, Brock M. Results of chronic subthalamic nucleus stimulation for Parkinson's disease: a 1-year follow-up study. Surg Neurol. (2002) 57:306-11. doi: 10.1016/S0090-3019(02)00691-2

54. Herzog J, Volkmann J, Krack P, Kopper F, Potter M, Lorenz D, et al. Two-year follow-up of subthalamic deep brain stimulation in Parkinson's disease. Mov Disord. (2003) 18:1332-7. doi: 10.1002/mds. 10518

55. Simuni T, Jaggi JL, Mulholland H, Hurtig HI, Colcher A, Siderowf AD, et al. Bilateral stimulation of the subthalamic nucleus in patients with Parkinson disease: a study of efficacy and safety. J Neurosurg. (2002) 96:66672. doi: $10.3171 /$ jns.2002.96.4.0666
56. Vingerhoets FJ, Villemure JG, Temperli P, Pollo C, Pralong E, Ghika J, et al. Subthalamic DBS replaces levodopa in Parkinson's disease: two-year follow-up. Neurology (2002) 8:396-401. doi: 10.1212/wnl.58.3.396

57. Fraix V, Pollak P, Van Blercom N, Xie J, Krack P, Koudsie A, et al. Effect of subthalamic nucleus stimulation on levodopa-induced dyskinesia in Parkinson's disease. Neurology (2000) 57:S60-2. doi: 10.1212/WNL.55.12.1921

58. Visser-Vandewalle V, Van der Linden C, Temel Y, Celik H, Ackermans L, Spince maille G, et al. Long-term effects of bilateral subthalamic nucleus stimulation in advanced Parkinson disease: a four year follow-up study. Parkinsonism Relat Disord. (2005) 11:157-165. doi: 10.1016/j.parkreldis.2004.10.011

59. Rodriguez-Oroz MC, Zamarbide I, Guridi J, Palmero MR, Obeso JA. Efficacy of deep brain stimulation of the subthalamic nucleus in Parkinson's disease 4 years after surgery: double blind and open label evaluation. J Neurol Neurosurg Psychiatr. (2004) 75:1382-5. doi: 10.1136/jnnp.2003.031294

60. Gervais-Bernard H, Xie-Brustolin J, Mertens P, Polo G, Klinger H, Adamec D, et al. Bilateral subthalamic nucleus stimulation in advanced Parkinson's disease: five year follow-up. J Neurol. (2009) 256:225-33. doi: 10.1007/s00415-009-0076-2

61. Paek SH, Yun JY, Song SW, Kim IK, Hwang JH, Kim JW, et al. The clinical impact of precise electrode positioning in STN DBS on three-year outcomes. J Neurol Sci. (2013) 327:25-31. doi: 10.1016/j.jns.2013.01.037

62. Merola A, Zibetti M, Angrisano S, Rizzi L, Ricchi V, Arusi CA, et al. Parkinson's disease progression at 30 years: a study of subthalamic deep brainstimulated patients. Brain (2011) 134:2074-84. doi: 10.1093/brain/awr121

63. Martinez-Martin P, Valldeoriola F, Tolosa E, Pilleri M, Molinuevo JL, Rumi A, et al. Bilateral subthalamic nucleus stimulation and quality of life in advanced Parkinson's disease. Mov Disord. (2002) 17:372-77. doi: 10.1002/mds.10044

64. Just $\mathrm{H}$, Ostergaard $\mathrm{K}$. Health-related quality of life in patients with advanced Parkinson's disease treated by deep brain stimulation of the subthalamic nuclei. Mov Disord. (2002) 17:539-45. doi: 10.1002/mds.10111

65. Lezcano E, Gomez-Esteban JC, Zarranz JJ, Lambari I, Madoz P, Bilbao G, et al. Improvement in quality of life in patients with advanced Parkinson's disease following bilateral deep-brain stimulation in subthalamic nucleus. Eur J Neurol. (2004) 11:451-54. doi: 10.1111/j.1468-1331.2004.00804.x

66. Sobstyl M, Zabek M, Górecki W, Mossakowski Z. Quality of life in advanced Parkinson's disease after bilateral subthalamic stimulation: 2 years follow-up study. Clin Neurol Neurosurg. (2014) 124:161-5. doi: 10.1016/j.clineuro.2014.06.019

67. Akbar U, He Y, Dai Y, Hack N, Malaty I, McFarland NR, et al. Weight loss and impact on quality of life in Parkinson's disease. PLoS ONE (2015) 10:e0124541. doi: 10.1371/journal.pone.0124541

68. Yoon JE, Kim JS, Jang W, Park J, Oh E, Youn J, et al. Gender differences of nonmotor symptoms affecting quality of life in Parkinson disease. Neurodegener Dis. (2017) 17:276-80. doi: 10.1159/000479111

69. Ardouin C, Pillon B, Peiffer E, Bejjani P, Limousin P, Damier P, et al. Bilateral subthalamic or pallidal stimulation for Parkinson's disease affects neither memory nor executive functions: a consecutive series of 62 patients. Ann Neurol. (1999) 46:217-23.

70. Witt K, Daniels C, Reiff J, Krack P, Volkmann J, Pinsker MO, et al. Neuropsychological and psychiatric changes after deep brain stimulation for Parkinson's disease: a randomised, multicentre study. Lancet Neurol. (2008) 7:605-14. doi: 10.1016/S1474-4422(08)70114-5

71. Funkiewiez A, Ardouin C, Caputo E, Krack P, Fraix V, Klingeret H, et al. Long term effects of bilateral subthalamic nucleus stimulation on cognitive function, mood, and behaviour in Parkinson's disease. J Neurol Neurosurg Psychiatry (2004).75:834-39. doi: 10.1136/jnnp.2002.009803

72. Janssen ML, Duits AA, Turaihi AH, Ackermans L, Leentjens AF, Leentjes $\mathrm{AF}$, et al. Subthalamic nucleus high-frequency stimulation for advanced Parkinson's disease: motor and neuropsychological outcome after 10 years. Stereotact Funct Neurosurg. (2014) 92:381-7. doi: 10.1159/000366066

73. Kulisevsky J, Berthier ML, Gironell A, Pascual-Sedano B, Molet J, Pares P, et al. Mania following deep brain stimulation for Parkinson's disease. Neurology (2002) 59:1421-24. doi: 10.1212/WNL.59.9.1421

74. Black KJ. Psychiatric screening for DBS. Parkinsonism Relat Disord. (2007) 13:546. doi: 10.1016/j.parkreldis.2006.12.007

75. Voon V, Fernagut PO, Wickens J, Baunez C, Rodriguez M, Pavon N, et al. Chronic dopaminergic stimulation in Parkinson's disease: from 
dyskinesias to impulse control disorders. Lancet Neurol. (2009) 8:1140-49. doi: 10.1016/S1474-4422(09)70287-X

76. Voon V, Mehta AR, Hallett M. Impulse control disorders in Parkinson's disease:recent advances.CurrOpinNeurol. (2011) 24:324-330. doi: 10.1097/WCO.0b013e3283489687

77. Silveira-Moriyama L, Evans AH, Katzenschlager R, Lees AJ. Punding and dyskinesias. Mov Disord. (2006) 21:2214-17. doi: 10.1002/mds.21118

78. Ardouin C, Voon V, Worbe Y, Abouazar N, Czernecki V, Hosseini $\mathrm{H}$, et al. Pathological gambling in Parkinson's disease improves on chronic subthalamic nucleus stimulation. Mov Disord. (2006) 21:1941-46. doi: $10.1002 / \mathrm{mds} .21098$

79. Hälbig TD, Tse W, Frisina PG, Baker BR, Hollander E, Shapiro H, et al. Subthalamic deep brain stimulation and impulse control in Parkinson's disease. Eur J Neurol. (2009) 16:493-7. doi: 10.1111/j.1468-1331.2008.02509.x

80. Moum SJ, Price CC, Limotai N, Oyama G, Ward H, Jacobson C, et al. Effects of STN and GPi deep brain stimulation on impulse control disorders and dopamine dysregulation syndrome. PLoS ONE (2012) 7:e29768. doi: 10.1371/journal.pone.0029768

81. Eusebio A, Witjas T, Cohen J, Fluchère F, Jouve E, Régis J, et al. Subthalamic nucleus stimulation and compulsive use of dopaminergic medication in Parkinson's disease. J Neurol Neurosurg Psychiatry (2013) 84:868-74. doi: 10.1136/jnnp-2012-302387

82. Hack N, Akbar U, Thompson-Avila A, Fayad SM, Hastings EM, Moro E, et al. Impulsive and compulsive behaviors in Parkinson Study Group (PSG) centers performing deep brain stimulation surgery. J Parkinsons Dis. (2014) 4:591-98. doi: $10.3233 /$ JPD-140357

83. Amami P, Dekker I, Piacentini S, Ferré F, Romito LM, Franzini A, et al. Impulse control behaviours in patients with Parkinson's disease after subthalamic deep brain stimulation: de novo cases and 3-year follow-up. $J$ Neurol Neurosurg Psychiatry (2015) 86:562-4. doi: 10.1136/jnnp-2013-307214

84. Merola A, Romagnolo A, Rizzi L, Rizzone MG, Zibetti M, Lanotte $\mathrm{M}$, et al. Impulse control behaviors and subthalamic deep brain stimulation in Parkinson disease. J Neurol. (2017) 264:40-48. doi: $10.1007 / \mathrm{s} 00415-016-8314-\mathrm{x}$

85. Vergani F, Landi A, Pirillo D, Cilia R, Antonini A, Sganzerla EP, et al. Surgical, Medical and Hardware Adverse Events in a Series of 141 Patients Undergoing Subthalamic Deep Brain Stimulation for Parkinson Disease. World Neurosurg. (2010) 73:338-44. doi: 10.1016/j.wneu.2010.01.017

86. Blomstedt P, Hariz MI. Hardware-related complications of deep brain stimulation: a ten year experience. Acta Neurochir. (2005) 147:1061-4. doi: 10.1007/s00701-005-0576-5

87. Videnovic A, Metman LV. Deep brain stimulation for Parkinson's disease: prevalence of adverse events and need for standardized reporting. Mov Disord. (2008) 23:343-9. doi: 10.1002/mds.21753
88. Hamani C, Lozano AM. Hardware-related complications of deep brain stimulation: a review of the published literature. Stereotact Funct Neurosurg. (2006) 84:248-51. doi: 10.1159/0000 96499

89. Obeso JA, Olanow CW, Rodriguez-Oroz MC, Krack P, Kumar R, Lang AE, et al. Deep-brain stimulation of the subthalamic nucleus or the pars interna of the globuspallidus in Parkinson's disease. N Engl J Med. (2001) 345:956-63. doi: 10.1056/NEJMoa000827

90. Lyons KE, Wilkinson SB, Overman J, Pahwa R. Surgical and hardware complications of subthalamic stimulation: a series of 160 procedures. Neurology (2004) 63:612-6. doi: 10.1212/01.WNL.0000134650.91974.1A

91. Oh MY, Abosch A, Kim SH, Lang AE, Lozano AM. Long-term hardwarerelated complications of deep stimulation. Neurosurgery (2002) 50:1268-74. doi: 10.1097/00006123-200206000-00017

92. Seijo FJ, Alvarez-Vega MA, Gutierrez JC, Fdez-Glez F, Lozano B. Complications in subthalamic nucleus stimulation surgery for treatment of Parkinson's disease. Review of 272 procedures. Acta Neurochir. (2007) 149:867-75. doi: 10.1007/s00701-007-1267-1

93. Umemura A, Jaggi JL, Hurtig HI, Siderowf AD, Colcher A, Stern MB, et al. Deep brain stimulation for movement disorders: morbidity and mortality in 109 patients. J Neurosurg. (2003) 98:779-84. doi: 10.3171/jns.2003.98.4.0779

94. Voges J, Waerzeggers Y, Maarouf M, Lehrke R, Koulousakis A, Lenartz D, et al. Deep-brain stimulation: Long-term analysis of complications caused by hardware and surgery-experiences from a single centre. J Neurol Neurosurg Psychiatry (2006) 77:868-72. doi: 10.1136/jnnp.2005.081232

Conflict of Interest Statement: The authors declare that the research was conducted in the absence of any commercial or financial relationships that could be construed as a potential conflict of interest.

The reviewer MJ declared a past co-authorship with one of the authors AbB to the handling Editor.

Copyright $\odot 2018$ Rahmani, Benabdeljlil, Bellakhdar, El Alaoui Faris, Jiddane, El Bayad, Boutbib, Razine, Gana, El Hassani, El Fatemi, Fikri, Sanhaji, Tassine, El Alaoui Balrhiti, El Hadri, Ech-cherif Kettani, El Abbadi, Amor, Moussaoui, Semlali, Aidi, Ait Benhaddou, Benomar, Bouhouche, Yahyaoui, El Khamlichi, El Ouahabi, El Maaqili, Tibar, Arkha, Melhaoui, Benazzouz and Regragui. This is an open-access article distributed under the terms of the Creative Commons Attribution License (CC $B Y)$. The use, distribution or reproduction in other forums is permitted, provided the original author(s) and the copyright owner(s) are credited and that the original publication in this journal is cited, in accordance with accepted academic practice. No use, distribution or reproduction is permitted which does not comply with these terms. 